\title{
Altered in vitro Proliferation of Mouse SOD1-G93A Skeletal Muscle Satellite Cells
}

\author{
Raquel Manzano ${ }^{a}$ Janne M. Toivonen ${ }^{a}$ Ana C. Calvo ${ }^{a}$ Sara Oliván ${ }^{a}$ \\ Pilar Zaragoza $^{\mathrm{a}}$ Clementina Rodellar $^{\mathrm{a}}$ Didier Montarras $^{\mathrm{b}}$ Rosario Osta ${ }^{\mathrm{a}}$ \\ a LAGENBIO-I3A, Aragon's Institute of Health Sciences, University of Zaragoza, Zaragoza, Spain; \\ bUnité de Génétique Moléculaire du Développement, Centre National de la Recherche Scientifique URA 2578, \\ Département de Biologie du Développement, Institut Pasteur, Paris, France
}

\section{Key Words}

Amyotrophic lateral sclerosis - Skeletal muscle •

Neurodegenerative disease $\cdot$ SOD1 mutants $\cdot$ Satellite cell •

Proliferation $\cdot$ Cell culture

\begin{abstract}
Background: Amyotrophic lateral sclerosis (ALS) is the most common adult-onset neurodegenerative disease characterized by ascending muscle weakness, atrophy and paralysis. Early muscle abnormalities that precede motor neuron loss in ALS may destabilize neuromuscular junctions, and we have previously demonstrated alterations in myogenic regulatory factor (MRF) expression in vivo and in the activation of myofiber-associated skeletal muscle satellite cells (SMSCs) in the mouse model of ALS (SOD1-G93A). Methods: To elucidate niche dependence versus cell-autonomous mutant SOD1 (mSOD1) toxicity in this model, we measured in vitro proliferation potential and MRF and cyclin gene expression in SMSC cultures derived from fast-twitch extensor digitorum longus and slow-twitch soleus muscles of SOD1-G93A mice. Results: SMSCs from early presymptomatic (p40) to terminal, semi-paralytic (p120) SOD1-G93A mice demonstrated generally lower proliferation potential compared with age-matched controls. However, induced proliferation
\end{abstract}

was observed in surgically denervated wild-type animals and SOD1-G93A animals at p90, when critical denervation arises. SMSCs from fast and slow muscles were similarly affected by mSOD1 expression. Lowered proliferation rate was generally corroborated with decreased relative MRF expression levels, although this was most prominent in early age and was modulated by muscle type origin. Cyclins controlling cell proliferation did not show modifications in their mRNA levels; however, the expression of cyclin-dependent kinase inhibitor 1A (Cdkn1a), which is known to promote myoblast differentiation, was decreased in SOD1-G93A cultures. Conclusions: Our data suggest that the function of SMSCs is impaired in SOD1-G93A satellite cells from the earliest stages of the disease when no critical motor neuron loss has been described.

Copyright @ 2012 S. Karger AG, Basel

\section{Introduction}

Amyotrophic lateral sclerosis (ALS) is a progressive, lethal neurodegenerative disease. The main hallmark of ALS is a selective death of motor neurons in the brain and spinal cord ultimately leading to the paralysis of voluntary muscles. Dysfunction of upper motor neurons causes

\section{KARGER \\ Fax +4161306 1234 \\ E-Mail karger@karger.ch}

www.karger.com (c) 2012 S. Karger AG, Basel

$1660-2854 / 13 / 0113-0153 \$ 38.00 / 0$

Accessible online at:

www.karger.com/ndd
Dr. Rosario Osta

LAGENBIO-INGEN

University of Zaragoza

C/ Miguel Servet 177, ES-50013 Zaragoza (Spain)

Tel. +34976 761 621, E-Mail osta@ unizar.es 
spasticity and hyperreflexia, whereas impairment of lower motor neurons triggers generalized muscle weakness, atrophy and paralysis [1]. Whereas the great majority of the ALS cases are considered as sporadic, about $10 \%$ of the cases are familial (fALS) with identified heritable genetic component. Approximately $10-15 \%$ of fALS are caused by mutations in $\mathrm{Cu} / \mathrm{Zn}$ superoxide dismutase (SOD1) gene [2]. A mouse model of ALS that overexpress glycine 93 to alanine (G93A)-mutated human $\mathrm{Cu} / \mathrm{Zn}$ superoxide dismutase (mSOD1 or SOD1-G93A) and develops motor neuron pathology similar to that observed in human fALS [3-5]. As mSOD1 can induce motor neuron apoptosis, it was hypothesized that its expression uniquely in these cells was sufficient to cause ALS. However, this theory has been questioned as targeted expression of mSOD1 specifically in motor neurons does not always lead to an ALS phenotype [6, 7]. Indeed, in chimeric animals harboring different proportions of cells expressing wild-type and mSOD1, the number of wild-type SOD1 expressing cells was positively associated with lifespan whether these cells were motor neurons or not [for review see 8]. In agreement with these findings, other tissues have been shown to be implicated in ALS; astrocytic activation and secretion of proteins toxic for motor neurons has been described in ALS patients [9] and ablation of microglial and macrophage lineage increases lifespan of mSOD1 mice [10]. Muscle cells may also play an active role in the pathobiology of ALS as one of the earliest signs of the disease is altered muscle metabolism [11, 12], followed by disruption of the neuromuscular junction and subsequent retrograde axonal degeneration leading to the motor neuron death [13]. Muscle alterations, such as increased nutrient uptake, modified carbohydrate, lipid metabolism and altered mitochondrial uncoupling and respiration take place before the first signs of motor neuron degeneration $[12,14,15]$. Therefore, certain muscle abnormalities seem to precede motor neuron death rather than resulting from it. Expression of insulin-like growth factor-1 (Igf1) specifically in skeletal muscle delays the disease in mSOD1 mice [16], and it was proposed that the effect of Igf1 is mediated through the activation of skeletal muscle satellite cells (SMSCs), committed muscle progenitors present in the periphery of adult muscle fibers [17]. In adults, SMSCs remain quiescent, expressing the satellite cell marker paired-box transcription factor Pax7 [18-21]. Upon distinct stimuli such as acute injury, exercise or muscle denervation, they activate [22], re-enter the cell cycle and start proliferating to coexpress Myod1 (myogenic differentiation 1) [23-25]. Subsequently, SMSCs up-regulate myogenin and elongate to form new myotubes to regenerate muscle $[22,26]$. Myod 1 and myogenin are known as myogenic regulatory factors (MRFs). These MRFs are muscle-specific members of the basic helix-loop-helix (bHLH) transcription factor superfamily [27] that heterodimerize with bHLH transcription factors named $\mathrm{E}$ proteins to drive the expression of key muscle genes such as muscle creatine kinase, troponin I, acetylcholine receptor $\alpha$-subunit and myosin heavy and light chains $[28,29]$. Recent work has described an abnormal senescent-like morphology and reduced myosin heavy chain isoform expression in myotubes obtained from in vitro myoblast cultures established from ALS patient-derived muscle biopsies [30]. The authors concluded that in ALS patients, SMSCs' ability to differentiate is severely impaired. Consistently, evidence recently published by us also suggests that MRF expression is altered in the skeletal muscle of SOD1-G93A mouse model [31], and that satellite cell number and activation status are altered [32]. Importantly, fiber type- and age-related differences were also reported [32].

Here, we investigated the proliferative potential and Pax7, MRF and cyclin gene expression in satellite cell cultures from extensor digitorum longus (EDL), mainly composed of fast-twitch myofibers (type II) and soleus (SOL), with slow-twitch myofibers (type I), from the early presymptomatic to the terminal phase of the disease in SOD1-G93A mice. We observed a consistent diminution in the SOD1-G93A SMSCs' ability to proliferate in both muscles under study and at all stages except in 90-day-old SMSC cultures where an increment existed. $\mathrm{Pax} 7$ and MRF expression was also modified according to proliferative potential except in the latest phases of the disease when a deregulation of these myogenic program factors was observed.

\section{Materials and Methods}

All experimental procedures were approved by the Ethics Committee of the University of Zaragoza, and followed the international guidelines for the use of laboratory animals. Mice were housed under a 12 -hour light/dark cycle at $21-23^{\circ} \mathrm{C}$ with relative humidity of $55 \%$. Food and water were available ad libitum. Animals were sacrificed by cervical dislocation.

\section{Satellite Cell Extraction and Culture}

Three male B6SJL and SOD1-G93A mice per age group were sacrificed at the early presymptomatic ( $\mathrm{p} 40$ ), late presymptomatic (p60), symptomatic (p90) and terminal stages (p120). EDL (fast-twitch) and SOL (slow-twitch) muscles were collected and processed in parallel. Muscle satellite cell extraction and culture were carried out following the described protocol [33, 34]. Pooled muscles per age and muscle type were minced to a slurry and 
digested in a solution of $0.1 \%$ trypsin and $0.1 \%$ collagenase $(w / v$; Sigma-Aldrich) for $30 \mathrm{~min}$ at $37^{\circ} \mathrm{C}$. The enzymatic reactions were stopped with $20 \%$ fetal bovine serum (Gibco) diluted in DMEM + GlutaMAX (Gibco), and three to four rounds of digestion were performed until the muscle bulk was digested completely. The cell suspension from each group was filtered through a $70-\mu \mathrm{m}$ diameter sterile strainer and centrifuged at $1,800 \mathrm{rpm}$ for $15 \mathrm{~min}$ at $4^{\circ} \mathrm{C}$. Cell pellet was resuspended in DMEM + GlutaMAX (Gibco) and stained with $0.4 \%$ trypan blue (Sigma-Aldrich) for viable cell counting. Cell proliferation and gene expression analysis were carried out in freshly isolated (passage zero) cells to avoid the possibility that mSOD1 SMSCs display altered susceptibility to freezing or trypsinization. For proliferation and gene expression analysis, a total of 1,000 cells were seeded in each well of a 96-well plate coated with Matrigel basement membrane matrix (Becton Dickinson SA). The culture medium was composed of 39\% F-12 + GlutaMAX (Gibco), 39\% DMEM + GlutaMAX (Gibco), 10\% fetal calf serum (Gibco) and $2 \%$ Ultroser G (Pall-Biosepra). Cells were left to adhere and start proliferating for 3.5 days at $37^{\circ} \mathrm{C}$ and $5 \% \mathrm{CO}_{2}$. At least four replicate wells were plated for each group of muscle type and age. Experiments were performed in parallel for cell proliferation and gene expression analysis.

\section{Cell Proliferation Assay}

Starting 3.5 days after the plating, and repeatedly every $24 \mathrm{~h}$ until 7.5 days, cell proliferation plate was fixed with $10 \%$ neutral buffered formalin solution (Sigma-Aldrich) for $15 \mathrm{~min}$, and nuclei were stained with Hoechst 33342 (Bis Benzimide H 33342 trihydrochloride, Sigma-Aldrich) for $5 \mathrm{~min}$. After fixation, cells were washed with $1 \times$ PBS, and five random fields per well were photographed under an epifluorescence microscope (Nikon TE2000-E) at $\times 20$ magnification and $325 \mathrm{~nm}$. For each time point, the total number of nuclei per replicate (total 20 fields) was manually counted for each group of muscle type and age. For each day of culture, data were compared with the corresponding muscle and age group of interest (see below for the statistics). Data of the four replicates were averaged and normalized setting the maximum value from each comparison to 100 . Error bars represent the standard error between replicates as percentage of the maximum value of the comparison that has been set to 100 .

\section{Quantification of Gene Expression}

Pax7 and Myod1 genes were analyzed as markers for satellite cell determination and activation, respectively, and Pcna and Ccnd 1 genes were analyzed as markers of cell cycle entry, at 5.5 days of culture when proliferation was prominent without significant differentiation $[21,35]$. The expression of cyclin-dependent kinase inhibitor 1A (Cdkn1a), a known target for Myod1 and myogenin and promoter of satellite cell differentiation, was also quantified [36]. Finally, myogenin mRNA, a marker of differentiation process, was measured at day 7.5 when clear myotube formation was observed.

Cells were washed with cold $1 \times$ PBS and transferred to $-80^{\circ} \mathrm{C}$ to wait for RNA extraction and cDNA synthesis. The plates were processed according to the instructions of Cells-to-cDNA kit (Ambion) instructions. Plates were thawed on ice, and cells were lysed by adding $100 \mu \mathrm{l}$ of cell lysis solution. To release RNA from cells and eliminate endogenous RNase activity, lysed cells were subjected to heat treatment for $15 \mathrm{~min}$ at $75^{\circ} \mathrm{C}$. Traces of genomic DNA were eliminated with Dnase treatment at $37^{\circ} \mathrm{C}$ for $15 \mathrm{~min}$, followed by $5 \mathrm{~min}$ of heat inactivation at $75^{\circ} \mathrm{C}$. cDNA synthesis reactions from each RNA sample were performed in duplicates as follows. Each reaction included a pool of $2 \mu \mathrm{l}$ of dNTPs, $1 \mu \mathrm{l}$ of random hexamers, and $5 \mu \mathrm{l}$ of RNA and was incubated at $75^{\circ} \mathrm{C}$ for $3 \mathrm{~min}$. Subsequently, $1 \mu \mathrm{l}$ of $10 \times$ reverse transcription buffer, $0.5 \mu \mathrm{l}$ M-MLV retrotranscriptase and $0.5 \mu \mathrm{l}$ RNase inhibitor were added and the reaction was incubated at $42^{\circ} \mathrm{C}$ for $60 \mathrm{~min}$ and then at $95^{\circ} \mathrm{C}$ for $10 \mathrm{~min}$. For QPCR, cDNA was diluted 1:10 in $\mathrm{dH}_{2} \mathrm{O}$, and $2 \mu \mathrm{l}$ were used as a template for each reaction $(3$ replicates per cDNA sample) containing $2.5 \mu$ l Fast $2 \times$ TaqMan master mix (No AmpErase UNG) and $0.5 \mu l$ gene-specific TaqMan assays (Applied Biosystems) for Pax7 (Mm00834079_m1), Myod1 (Mm00440387_m1), Pcna (proliferating cell nuclear antigen)(Mm00448100_g1), Ccnd1 (cyclin d1)(Mm00432359_m1), Cdkn1a (cyclin-dependent kinase inhibitor 1A)(Mm00432448_ $\mathrm{m} 1$ ) or myogenin (Mm00446194_m1) in a final volume of $5 \mu \mathrm{l}$. Reactions were run using StepOne Plus Real-Time PCR System (Applied Biosystems) using the following conditions; $95^{\circ} \mathrm{C}$ for $10 \mathrm{~min}$ and $47 \mathrm{cycles}$ of $95^{\circ} \mathrm{C}$ for $15 \mathrm{~s}$ and $60^{\circ} \mathrm{C}$ for $30 \mathrm{~s}$. In each cDNA sample, three endogenous reference genes were amplified using TaqMan assays: $18 \mathrm{~S}$ ribosomal RNA (4352930E), Gapdh (4352932E), and $\beta$-actin (4352933E). Target gene expression results were normalized using geometric mean of these three housekeeping genes [37-39], and relative gene expression was determined using the 2- $\Delta \Delta$ CT method and the data from the wild-type derived cultures for each group as calibrator [40]. For all primer/ probe sets, reaction efficiencies approached $100 \%$.

\section{Muscle Denervation Procedure}

Six male mice (B6CLJ strain) at p60 were anaesthetized (pentobarbital $30 \mathrm{mg} / \mathrm{kg}$, i.p.), and the right leg muscle denervation was performed by extraction of a $5-\mathrm{mm}$ segment of the sciatic nerve through an incision in the mid-posterolateral area of the thigh. The left limb remained unoperated, and was used as a control. The incision was closed with silk sutures and washed daily with antibacterial solution to prevent infection. The absence of toe-spread reflex was confirmed daily. Fifteen days after surgical denervation (age p75), the animals were sacrificed by cervical dislocation, and control and denervated EDL and soleus muscles were harvested and processed as described above.

\section{Immunofluorescence}

One well per group was fixed and immunofluorescence for MYOD was performed in order to ensure the myogenic origin of the cells. Cells were rinsed with PBS and fixed in neutral buffered formalin solution 10\% (Sigma-Aldrich) for $10 \mathrm{~min}$ at room temperature. Permeabilization was performed by incubating cells in a solution composed of $0.2 \%$ (v/v) Triton X-100 (Sigma-Aldrich) and $50 \mathrm{mM} \mathrm{NH}_{4} \mathrm{Cl}$ for $10 \mathrm{~min}$ and saturation for $10 \mathrm{~min}$ with $0.2 \%$ $(\mathrm{w} / \mathrm{v})$ gelatine in PBS. Primary antibody for MYOD (sc-304, Santa Cruz Biotechnology) was added 1:100 in PBS for $2 \mathrm{~h}$ at room temperature and visualized with Alexa 546-conjugated anti-rabbit secondary antibody 1:300 (Invitrogen). Nuclei were stained with $1,000 \mathrm{ng} / \mathrm{ml}$ Hoechst 33342 (Sigma-Aldrich) and mounted in Fluokeep mounting medium for immunofluorescence (Argene). All cultures used in this study showed a MYOD-positive content of $70-80 \%$. 


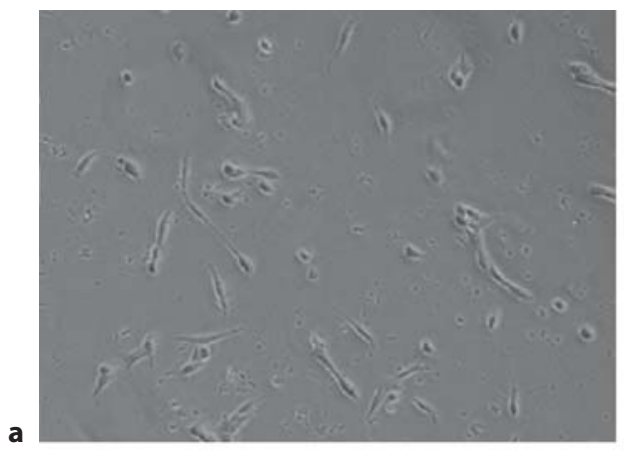

Day 3.5

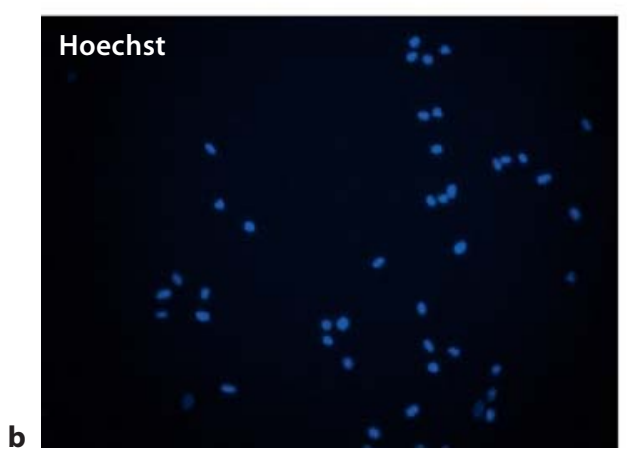

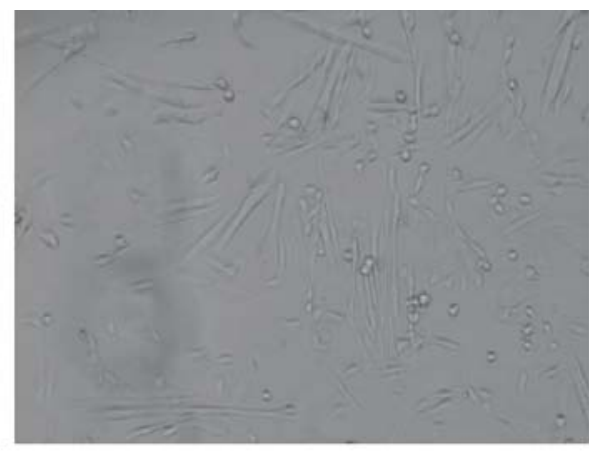

Day 7.5

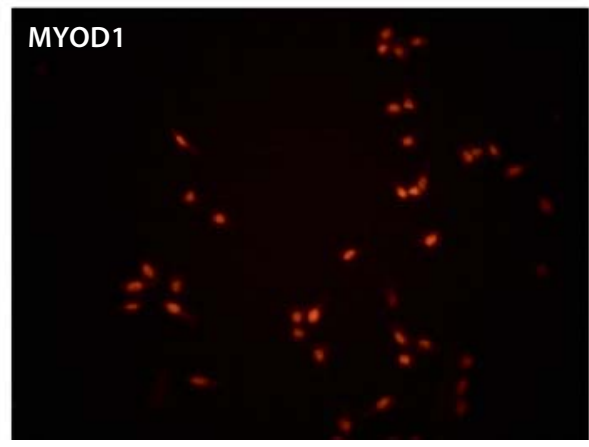

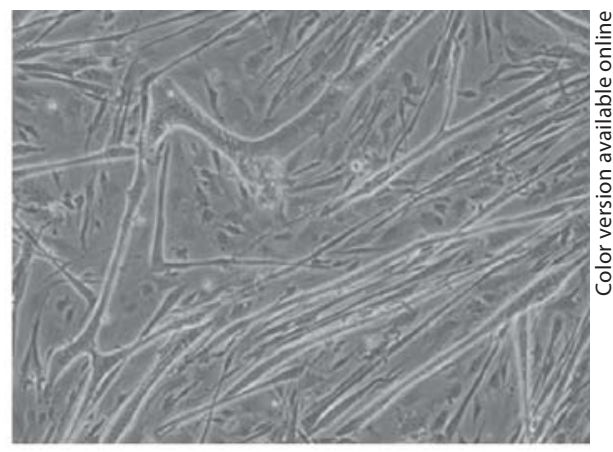

Day 10

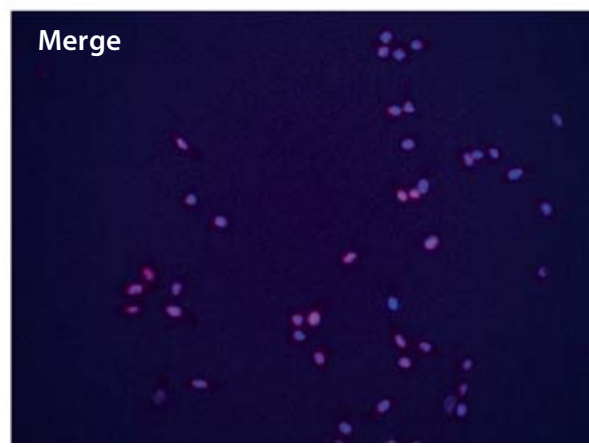

Fig. 1. Proliferation and differentiation process of mouse myogenic cell cultures. a Photographs show the in vitro appearance of satellite cell cultures 3.5, 7.5 and 10 days after plating. $\mathbf{b}$ The myogenicity of the cells was assessed 4.5 days after plating by costaining for Hoechst and immunofluorescence analysis for MYOD. MYODpositive cells at this stage represented $70-80 \%$ of the population.

\section{Statistical Analysis}

In the proliferation assay data analysis, total cells from five photographic fields of a single replicate well were manually counted, and the mean and standard error of mean for each group was calculated from the value of four replicate wells (total 20 fields per data points). For the relative quantitative PCR, statistical analysis was performed on the data obtained from the two cDNA synthesis reactions from each well and two biological replicate wells (total 4 data per group). Results obtained from SOD1-G93A and control groups were compared using Student's t test (Statistica 5.0, Statsoft software) [31]. Statistical differences were considered significant at $\mathrm{p}<0.05$.

\section{Results}

To assess the myogenic origin of the cells, cultures were maintained for 10 days in conditions that supported both proliferation and differentiation; fully developed myotubes were observed at the end of this period (fig. 1a). Additionally, based on immunostaining for MYOD at 4.5 days, all cultures used in the experiments showed 7080\% MYOD-positive cells (fig. 1b).
Despite a slight tendency at advanced culture days, no clear proliferative differences were observed between wild-type and SOD1-G93A in the case of EDL-derived SMSCs cultures at $\mathrm{p} 40$ (fig. 2a). By contrast, SOL-derived SMSCs from SOD1-G93A mice at $\mathrm{p} 40$ proliferated slower than their wild-type littermates (fig. 2b). At late presymptomatic day p60, SOD1-G93A cells proliferated slower than wild-type SMSCs in both muscles under study (fig. 2c, d). Surprisingly, at symptomatic day p90, SMSCs derived from both EDL and SOL muscles proliferated faster than those obtained from control littermates, although the substantial sample variation precluded significance in the case of EDL (fig. 2e, f). However, SMSCs from animals of 120 days of age, where muscle atrophy is already severe, proliferated again slower than their agematched wild-type SMSCs (fig. 2g, h).

To depict to what extent denervation influenced SMSCs proliferation, surgically denervated wild-type mice SMSCs were analyzed. SMSCs derived from EDL and SOL muscles of denervated limb displayed a superior proliferation rate compared to the SMSCs derived from 
Fig. 2. Growth curves from wild-type and SOD1-G93A mouse satellite cell cultures. Pairwise comparison of the satellite cell culture proliferation curves obtained from SOD1-G93A and wild-type muscles at p40 (early presymptomatic stage) EDL (a) and SOL (b), p60 (late presymptomatic stage) EDL (c) and SOL (d), p90 (symptomatic stage) EDL (e) and SOL (f) and p120 (terminal stage) EDL (g) and SOL (h), and from denervated EDL (i) and SOL (j) muscles. ${ }^{*} \mathrm{p}<0.05,{ }^{* *} \mathrm{p}<0.01$, Student's t test.
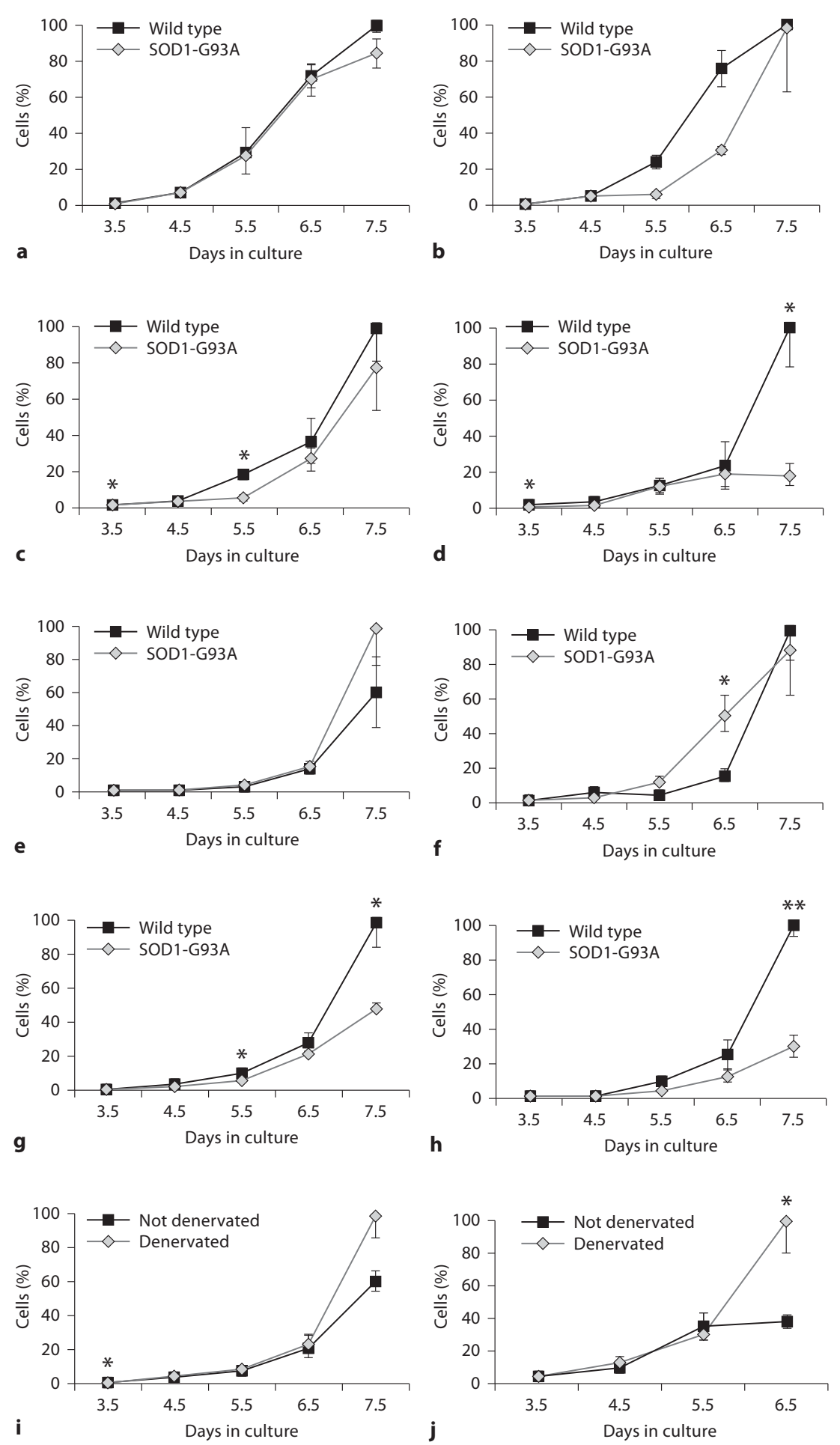

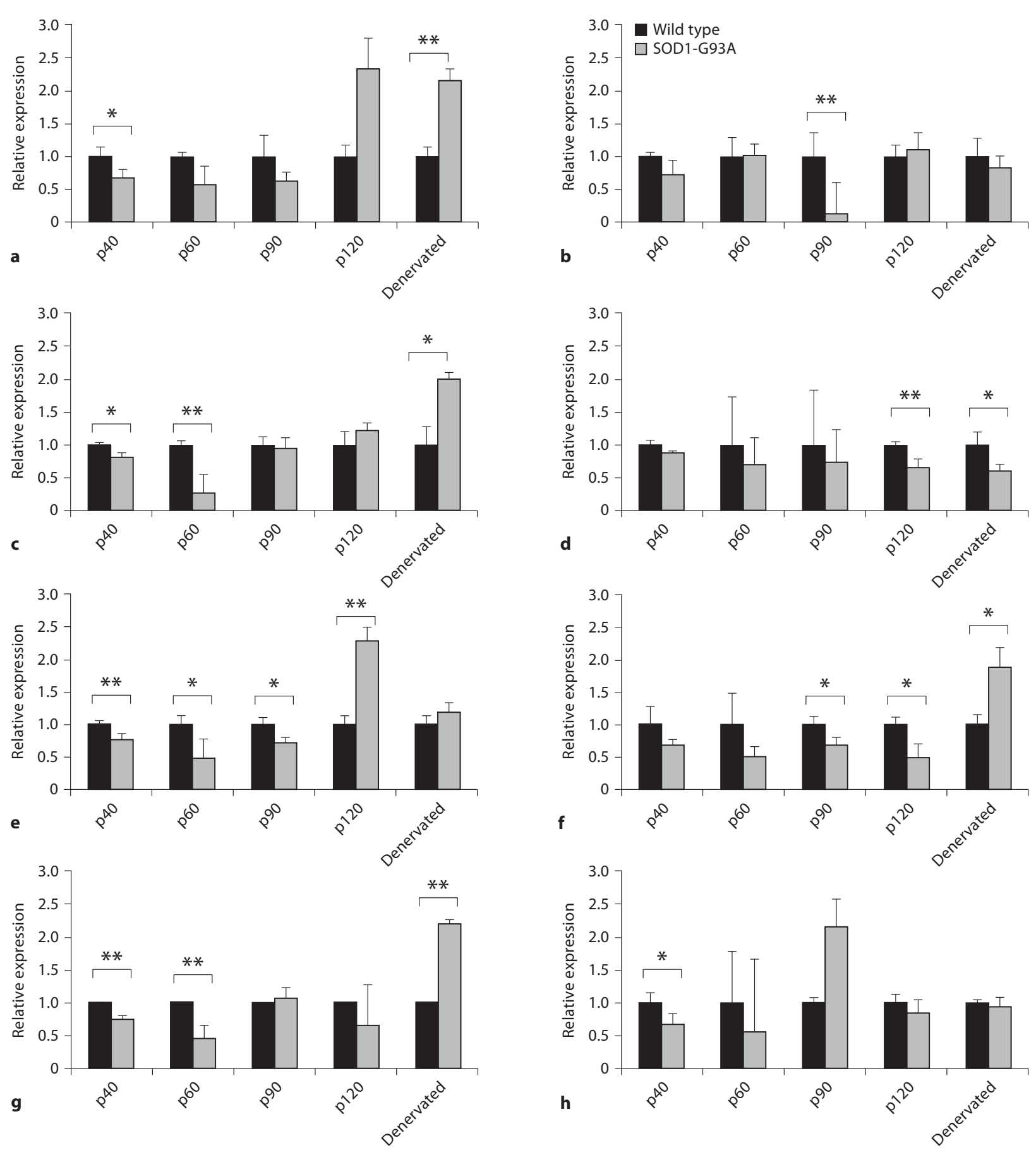

Fig. 3. Pax7, Myod1, Cdkn1a and myogenin expression in satellite cell cultures. Pax7 (a and b), Myod1 (c and d), Cdknla (e and $\mathbf{f})$ and myogenin (g and $\mathbf{h}$ ) levels in proliferating and differentiating satellite cells from EDL (a, $\mathbf{c}, \mathbf{e}, \mathbf{g})$ and SOL (b, d, f, h) muscles. In each panel, relative expression in cells from SOD1-G93A (light grey bars) and age-matched wild-type mice (black bars) at p40, p60, p90 and p120 are shown. Additionally, expression in denervated compared with intact muscles from the same animal are shown. Analysis was performed 5.5 (a, b, c, d, e and $\mathbf{f}$ ) and 7.5 days ( $\mathbf{g}$ and $\mathbf{h}$ ) after plating. ${ }^{*} \mathrm{p}<0.05,{ }^{* *} \mathrm{p}<0.01$, Student's test. 
the unoperated limb (fig. 2i, j). This supports the view that gross denervation at the onset of the disease symptomatic stage (p90) in SOD1-G93A mice may have stimulatory effects on SMSC proliferation rate.

Although all data points did not reach significance, the overall conclusion is that SMSCs derived from SOD1G93A mice proliferate at a lower rate compared to their wild-type-controls. This tendency is maintained from the early presymptomatic to the terminal stages of the disease in both muscle types studied. However, at the symptomatic stage, the proliferation rate is increased in mSOD1 SMSCs, a result that parallels the one observed in SMSCs derived from denervated muscle. It is of interest to note that even if the fast and slow muscles are unequally affected in the mice, the in vitro proliferation of SOD1-G93A SMSCs derived from both types of muscles are similarly affected compared to the age-matched wild type.

To get insight into the molecular mechanisms that may drive the observed impaired proliferative potential in SOD1-G93A satellite cells, we analyzed the expression of MRFs and cyclins implicated in the satellite cell determination and myogenic program (see Materials and Methods). At p40, SOD1-G93A SMSCs derived from EDL muscles presented a diminution in the levels of Pax7 mRNA (fig. 3a, p < 0.05) compared to wild-type cells. This result was correlated with decreased Myod1 (fig. 3c, $\mathrm{p}<0.05$ ), Cdknla (fig. 3e, p <0.01) and myogenin mRNA levels (fig. 3g, $\mathrm{p}<0.01$ ). In SOL-derived SMSCs, similar tendency to diminution in the levels of Pax7 mRNA (fig. 3b), Myod1 (fig. 3d) and Cdknla (fig. 3f) was accompanied with significantly reduced myogenin mRNA levels (fig. $3 \mathrm{~h}, \mathrm{p}<0.05$ ). Qualitatively similar results were obtained at the late presymptomatic stage (p60). Although Pax7 diminution was only suggestive (fig. 3a), levels of Myod1, Cdkn1a and myogenin remained reduced in EDL SMSCs (fig. $3 c, p<0.01$, fig. $3 e, p<0.05$, and fig. $3 g$, $\mathrm{p}<0.01$, respectively). On the other hand, $\operatorname{Pax} 7 \mathrm{mRNA}$ in SOL cultures was not altered (fig. 3b), and reduction in Myod1, Cdkn1a and myogenin was suggestive but nonsignificant (fig. $3 \mathrm{~d}, \mathrm{f}$ and $\mathrm{h}$, respectively).

At the onset of symptoms (p90), when SOD1-G93A SMSCs displayed similar or relatively increased proliferation (fig. 2e, f), similar levels of Myod1 mRNA were observed in mSOD1 SMSCs compared to the control in EDL (fig. 3c) and, in spite of the lower levels of Cdkn1a transcripts in SOD1-G93A cells (EDL, fig. 3e, $p<0.05$ and SOL, fig. 3f, $\mathrm{p}<0.05$ ), myogenin expression reached wildtype levels in EDL (fig. 3g) and even showed tendency to increment in SOL (fig. 3h) cultures. This increase in acti- vation and differentiation markers was accompanied with decreased SMSCs quiescence marker Pax7 (EDL, fig. 3a, and SOL, fig. 3b, p<0.01), being the downregulation of $P a x 7$, an essential condition to induce differentiation of satellite cells $[41,42]$. Finally, at the terminal stage (p120), a suggestive increment of Pax7 and Cdkn1a and less pronounced in Myod1 transcripts was observed in EDL-derived mSOD1 cells (Pax7, fig. 3a; Myod1, fig. 3c, and $C d k n 1 a$, fig. $3 \mathrm{e} ; \mathrm{p}<0.01)$; however, results showed a tendency to diminution of myogenin mRNA (fig. 3g). In mSOD1 SOL satellite cell cultures, $\operatorname{Pax} 7$ transcripts remained as in controls (fig. 3b); however, Myod1, Cdknla and myogenin factors revealed a tendency or significant reduction in mutant cell cultures (Myod1, fig. 3d; Cdkn1a, fig. 3f, $\mathrm{p}<0.05$, and myogenin, fig. $3 \mathrm{~h}$ ). On the other hand, EDL-derived SMSC cultures from denervated limbs expressed higher levels of the factors analyzed, Pax7, Myod1, Cdkn1a and myogenin (Pax7, fig. 3a, p < 0.01; Myod1, fig. $3 \mathrm{c}, \mathrm{p}<0.05$; Cdkn1a, fig. 3e, and myogenin, fig. $3 \mathrm{~g}$, $\mathrm{p}<0.01)$. Nevertheless, SMSCs from denervated SOL cultures showed a tendency to decrease for $\operatorname{Pax} 7$ (fig. 3b) and Myod1 transcripts (fig. 3d, p < 0.05), but again Cdkn1a and myogenin were upregulated (fig. $3 \mathrm{f}, \mathrm{p}<0.05$ ) or reached levels of wild-type cells (fig. $3 \mathrm{~h}$ ), respectively.

No significant differences were found in Pcna or Ccnd1 expression between SOD1-G93A and wild-type cell cultures at any of the studied stages and muscles (fig. 4), except in the case of Ccnd1 at p120 in EDL cultures, where SOD1-G93A cells, in coincidence with Myod1 tendency, showed significant upregulation (fig. $4 \mathrm{c}, \mathrm{p}<0.05$ ).

To summarize, SMSCs obtained from EDL and SOL muscles of SOD1-G93A mice cultured in vitro presented diminished levels of Pax7, MRFs and Cdknla mRNA at the early and late presymptomatic stages, although this was less obvious in SOL-derived SMSCs. The onset of symptomatic period coincided with increase to the wildtype level of Myod1 and myogenin, although Pax7 and $C d k n 1 a$ remained at relatively lower level. Finally, at the terminal stage, $\operatorname{Pax} 7$ levels remained incremented especially in EDL-derived SMSCs. Myod1 mRNA tended to increase in EDL and decrease in SOL, whereas myogenin transcripts tended to decrease in both SMSC cultures as in the earliest phases of the disease.

\section{Discussion}

In the SOD1-G93A model of ALS, the main signs of muscle pathology start at around 40 days of age with aggregation of mSOD1 proteins [43], loss of functional mo- 


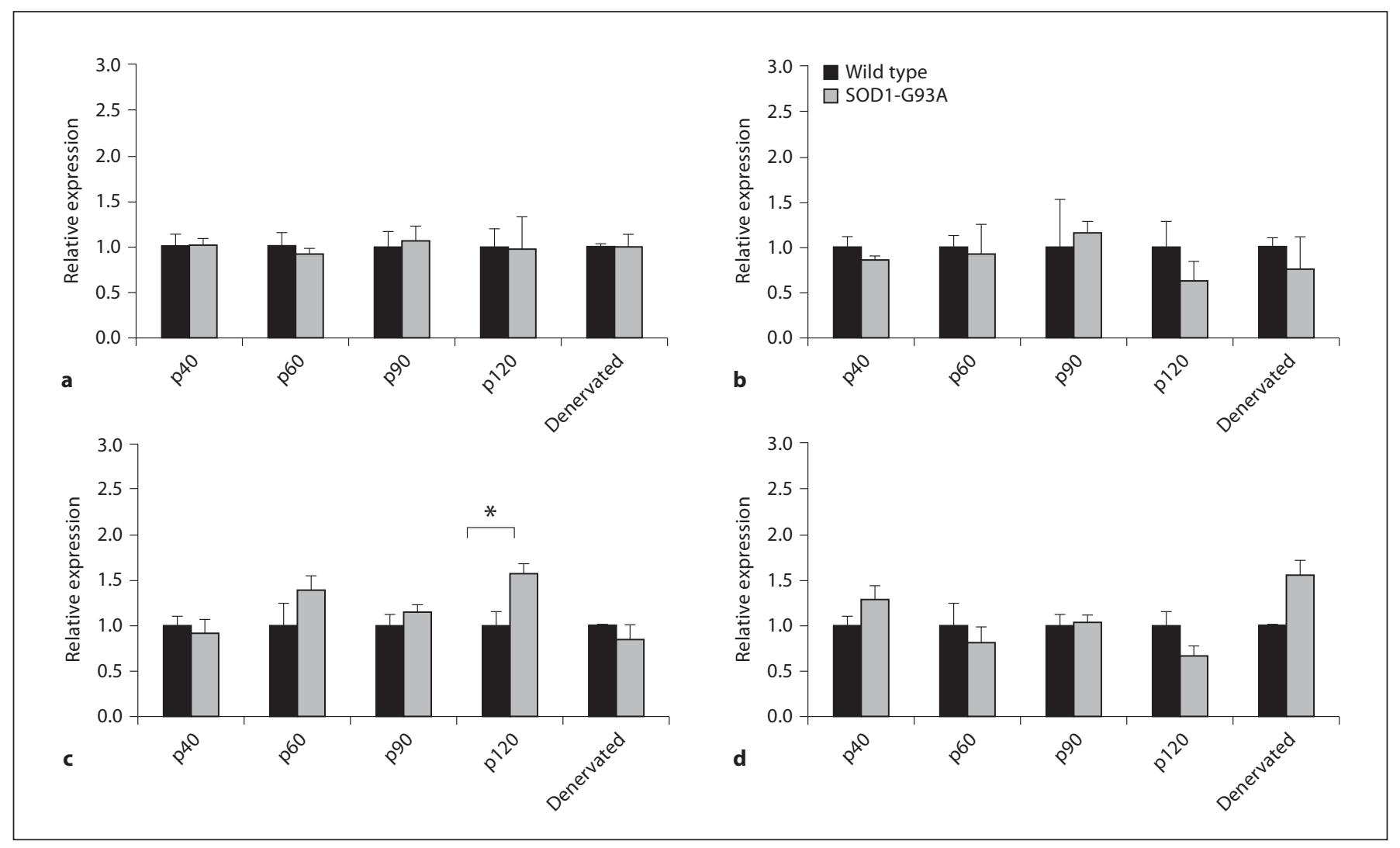

Fig. 4. Pcna and Ccnd1 expression in satellite cell cultures. Pcna (a and b) and Ccnd1 (c and d) levels in proliferating and differentiating satellite cells from EDL (a and $\mathbf{c}$ ) and SOL (b and $\mathbf{d}$ ) muscles. In each panel, relative expression in cells from SOD1-G93A (light grey bars) and age-matched wild-type mice (black bars) at p40, p60, p90 and p120 is shown. Additionally, expression in denervated compared with intact muscles from the same animal is shown. Analysis was performed 5.5 days after plating. ${ }^{*} \mathrm{p}<0.05,{ }^{* *} \mathrm{p}<0.01$, Student's t test.

tor units $[44,45]$ and reduction in the muscle contractile force [46]. The symptomatic stage starts at approximately 90 days of age with hind limb muscle weakness and fine tremors, and progresses to muscle atrophy and paralysis towards the terminal stage at approximately 120 days of age [47]. In pooled hind limb muscles, these changes are accompanied by transcriptional upregulation of MRF indicative of attempted regenerative response [31]. However, muscle fiber type differences have been described in the time course and severity of the mSOD1 muscle pathology $[44,45,48]$. We have recently described mSOD1induced regenerative response of SMSCs in both fast and slow-twitch skeletal muscle fibers in situ [32]. However, whether the observed alterations in the number and activation of SMSCs pool in mSOD1 myofibers during the course of the disease arise from signals from the cellular niche or represent a cell-autonomous effect of mSOD1 to SMSCs function remains obscure. To this end, we inves- tigated here the SMSCs proliferation and Pax7, MRF (Myod1 and myogenin) and cyclin expression in SMSC cultures established from SOD1-G93A and wild-type mice from the phenotypically unaffected ( $\mathrm{p} 40)$ to the semi-paralytic terminal stage (p120). This enabled us to determine the capacity of these cells to proliferate and follow the MRF expression in the absence of trophic or inhibitory signals from the natural SMSCs niche as well as those derived from altered electrical stimulation by connected neurons. Because muscle type susceptibility to mSOD1 toxicity varies in vivo, in our study we used typical fast-twitch EDL composed of approximately half and half of fast glycolytic (type IIb) and fast oxidative-glycolytic (type IIa) fibers, as well as slow-twitch SOL containing approximately $60 \%$ slow oxidative (type I) fibers and $40 \%$ type IIa fibers [49].

In early presymptomatic as well as late presymptomatic stage cultures, a tendency towards lower proliferative 
potential of SOD1-G93A satellite cells was observed in both muscles. On the other hand, diminished levels of MRFs and Cdknla were found, although sample variability prevented differences from being significant, especially in SOL-derived cultures. Our results parallel those of the earlier report of limited myogenicity in satellite cell cultures obtained from deltoid muscle biopsies in 7 ALS patients [30]. These authors observed an impaired myotube development in vitro, which is in agreement with our finding of decreased myogenin and Cdknla levels, both factors promoting satellite cell differentiation.

In our study, the onset of the symptomatic stage (p90) was associated with increased proliferation rate in mSOD1 carrying cells of both muscles under study. MRF gene expression roughly correlated with these findings: Myod1 reached similar levels to wild-type cells, especially in EDL muscle, and myogenin shifted towards increment, especially in SOL-derived SOD1-G93A cultures. Pax 7 is an accepted satellite cell marker [18-21]; therefore, the increment of this cell population would be directly expected to lead to an increase in $P a x 7$ transcripts. However, this statement is not so straightforward, because Pax7 downregulation is also necessary for satellite cell differentiation [41, 42]. Therefore, the observed Pax7 transcript decrement in SOD1-G93A satellite cells during the symptomatic stage (p90) must be an interplay between the increased number of Pax7-expressing satellite cells and the downregulation of this factor to allow cell cycle exit and myoblast differentiation since by this stage, a critical loss of motor units and tetanic force and muscle disturbance has been described in both EDL and SOL muscles [13, 45, 50, 51]. Proliferation and turnover of SMSCs at high rate for at least one month after denervation has also been reported $[52,53]$. Therefore, we suggest that denervation at the onset of the symptoms may temporarily stimulate satellite cell proliferation, and counteract the decreased proliferation rate caused by cell-autonomous mSOD1 toxicity observed at earlier phases of the disease. Finally, at the terminal stage (p120), a diminished proliferation capacity was observed for SOD1-G93A SMSCs of fast- and slow-twitch muscles. At the molecular level, $P a x 7$ showed tendency for increased mRNA expression, especially in EDL, possibly reflecting the grave denervation at this stage. However, whereas Myod1 and Cdkn1a remained upregulated in EDL cultures, in SOL cultures they became downregulated, showing the heterogeneous myogenic response to denervation or mSOD1 insults. Finally, myogenin displayed marked tendency to be reduced in satellite cell cultures at this stage in agreement with the abortive myogenesis described in ALS pa- tient-derived cells [30] and in denervated skeletal muscle [54].

Several factors may contribute to reduction in the proliferative potential of $\mathrm{mSOD} 1$ satellite cells. These include interactions between G93A-SOD1 and Bcl-2 through the cyclin regulator p27 and deregulation of cell cycle [55]. Additionally, mSOD1 aggregates may inhibit proteasomal machinery and deregulate cellular activities such as protein folding and organelle function (Golgi, endoplasmic reticulum, and mitochondria). On the other hand, mSOD1 impairment has been shown to induce oxidative stress and excessive and aberrant ROS chemistry [for review see 2], oxidative species being inhibitors of myogenesis [56-58]. Because Ccnd1 and Pcna, both factors involved in early induction of DNA replication upstream MRF function [36, 59], were not significantly affected in mSOD1 cultures, it is likely that the disruption of the molecular events leading to mSOD1 satellite cell proliferation is located downstream those factors. Alternatively, considering that the regulation of Pcna and Ccnd1 is mediated, in part, through the ubiquitin-proteasomal pathway [60], which has been shown to be altered in ALS patients and animal models [for review see 61], it is feasible that the modification of Pcna or Ccnd 1 function is a postranslational event in SOD1-G93A satellite cell cultures.

On the other hand, Cdknla is a promoter of cell cycle arrest; therefore, under physiological conditions, a reduced cellular proliferative capacity would be expected to be correlated with the upregulation of this factor. However, Myod and myogenin-induced expression of Cdkn1a also inhibits cyclin-dependent kinase activity to enable myocyte terminal differentiation $[62,63]$. Hence, mSOD1 satellite cells in presymptomatic mice may experiment a reduction in their proliferative capacity, as above discussed, and a disturbed ability to differentiate, as reflected in the Cdknla and myogenin downregulation and as previously suggested in ALS patients [30].

Muscle type susceptibility to mSOD1 toxicity varies $[44,45,64]$, and distinct regenerative response has been shown in fast- and slow-twitch myofibers from electrically stimulated [65], denervated and tetrodotoxin-treated muscles [66] and in SOD1-G93A mice [32]. One could, therefore, expect that myogenic cell cultures obtained from fast and slow myofibers of SOD1-G93A mice present differences at the functional and molecular levels. However, compared to the age-matched controls, mSOD1 SMSCs obtained from both fast and slow muscles displayed similar, although pathological state-dependent pattern of proliferation and MRF and Cdknla expression during the presymtomatic phases, when no severe dener- 
vation has been described. Because mSOD1 in the used model is expressed at similar levels in slow and fast muscles [32, 67], muscle type susceptibility to $\mathrm{mSOD} 1$ toxicity is probably directly linked to the distinct characteristics of motor neurons innervating type I and type II myofibers.

On the other hand, the observed impaired proliferative ability of mSOD1 satellite cells prompted us to decipher if myogenic differentiation was also disturbed in these cells. Although this was not the main purpose of the present study, myotube formation was observed in satellite cell cultures derived from SOD1-G93A mice at all the studied stages (online suppl. fig. 1; for all online suppl. material, see www.karger.com/doi/10.1159/000338061). Moreover, previous studies performed in our group, maintaining the mSOD1 satellite cells in culture for 10 days demonstrated the formation of fully developed myotubes that occasionally contracted (see a video in the supplementary material of Manzano et al. [32]). However, the significant downregulation of Cdknla and myogenin, factors involved in differentiation induction [36], during the presymptomatic stages of the disease in MSOD1 cultures, indicates, at least, an abnormal induction of the myogenic program at the molecular level. Further studies will be necessary to confirm if the observed myotubes are fully functional or present the characteristics of wild-type cells.

To conclude, our data are consistent with the view that SMSC performance in both fast and slow muscles of the
SOD1-G93A muscle is disturbed. This is likely to be a cell-autonomous consequence of mSOD1 toxicity and not solely dependent on neuromuscular junction destruction or muscle niche input. In contrast, it is likely that the preferential fast muscle susceptibility in ALS mainly arises from signals at the cellular niche in vivo and from characteristics of innervating motor neurons, and not from differential effects of mSOD1 in these two muscle fiber types. To our knowledge, this is the first study demonstrating in vitro proliferation of SMSCs in a widely used mouse ALS model. Further studies are warranted to decipher which cellular mechanisms contribute to the impaired satellite cell proliferation and to further test whether these results apply to SOD1-G93A from very young animals or if prolonged postnatal time is required for $\mathrm{mSOD} 1$ toxicity. In conjunction, we consider our novel results of significant value to guide future research on muscle-targeted therapies for ALS.

\section{Acknowledgements}

We apologize to those authors whose relevant work was not cited due to size restriction. We thank María Royo and Mamen Carreras (Microscopy and Image Service) for technical assistance with fluorescence microscope, and the I+CS (Aragon Health Sciences Institute) for access to the microscope, and Juan Antonio Castillo for his valuable logistic support. The study was funded by grants Caja Navarra: 'Tú eliges, tú decides'; PI071133 and PI10/0178 from the Fondo de Investigación Sanitaria of Spain, and PAMER from the Instituto Aragonés de Ciencias de la Salud (PIPAMER 09/09).

\section{References}

1 Rowland LP: Diagnosis of amyotrophic lateral sclerosis. J Neurol Sci 1998;160(suppl 1):S6-S24.

2 Pasinelli P, Brown RH: Molecular biology of amyotrophic lateral sclerosis: insights from genetics. Nat Rev Neurosci 2006;7:710-723.

-3 Gurney ME, Pu H, Chiu AY, Dal Canto MC, Polchow CY, Alexander DD, Caliendo J, Hentati A, Kwon YW, Deng HX, et al: Motor neuron degeneration in mice that express a human $\mathrm{Cu}, \mathrm{Zn}$ superoxide dismutase mutation. Science 1994;264:1772-1775.

4 Kato S: Amyotrophic lateral sclerosis models and human neuropathology: similarities and differences. Acta Neuropathol 2008;115:97114.
5 Miana-Mena FJ, Munoz MJ, Yague G, Men$\operatorname{dez}$ M, Moreno M, Ciriza J, Zaragoza P, Osta R: Optimal methods to characterize the G93A mouse model of ALS. Amyotroph Lateral Scler Other Motor Neuron Disord 2005; 6:55-62.

6 Lino MM, Schneider C, Caroni P: Accumulation of SOD1 mutants in postnatal motoneurons does not cause motoneuron pathology or motoneuron disease. J Neurosci 2002; 22:4825-4832.

7 Pramatarova A, Laganiere J, Roussel J, Brisebois K, Rouleau GA: Neuron-specific expression of mutant superoxide dismutase 1 in transgenic mice does not lead to motor impairment. J Neurosci 2001;21:3369-3374.

-8 Gonzalez de Aguilar JL, Echaniz-Laguna A, Fergani A, Rene F, Meininger V, Loeffler JP, Dupuis L: Amyotrophic lateral sclerosis: all roads lead to Rome. J Neurochem 2007;101: 1153-1160.
\9 Barbeito LH, Pehar M, Cassina P, Vargas MR, Peluffo H, Viera L, Estevez AG, Beckman JS: A role for astrocytes in motor neuron loss in amyotrophic lateral sclerosis. Brain Res Brain Res Rev 2004;47:263-274.

10 Boillee S, Yamanaka K, Lobsiger CS, Copeland NG, Jenkins NA, Kassiotis G, Kollias G, Cleveland DW: Onset and progression in inherited ALS determined by motor neurons and microglia. Science 2006;312:1389-1392.

11 Bouteloup C, Desport JC, Clavelou P, Guy N, Derumeaux-Burel H, Ferrier A, Couratier P: Hypermetabolism in ALS patients: an early and persistent phenomenon. J Neurol 2009; 256:1236-1242. 
$\checkmark 12$ Dupuis L, Oudart H, Rene F, Gonzalez de Aguilar JL, Loeffler JP: Evidence for defective energy homeostasis in amyotrophic lateral sclerosis: benefit of a high-energy diet in a transgenic mouse model. Proc Natl Acad Sci USA 2004;101:11159-11164.

-13 Fischer LR, Culver DG, Tennant P, Davis AA, Wang M, Castellano-Sanchez A, Khan J, Polak MA, Glass JD: Amyotrophic lateral sclerosis is a distal axonopathy: evidence in mice and man. Exp Neurol 2004;185:232240.

14 Dupuis L, Gonzalez de Aguilar JL, EchanizLaguna A, Eschbach J, Rene F, Oudart H, Halter B, Huze C, Schaeffer L, Bouillaud F, Loeffler JP: Muscle mitochondrial uncoupling dismantles neuromuscular junction and triggers distal degeneration of motor neurons. PLoS One 2009;4:e5390.

15 Dupuis L, Gonzalez de Aguilar JL, Oudart H, de Tapia M, Barbeito L, Loeffler JP: Mitochondria in amyotrophic lateral sclerosis: a trigger and a target. Neurodegener Dis 2004; $1: 245-254$.

- 16 Dobrowolny G, Giacinti C, Pelosi L, Nicoletti C, Winn N, Barberi L, Molinaro M, Rosenthal N, Musaro A: Muscle expression of a local IGF-1 isoform protects motor neurons in an ALS mouse model. J Cell Biol 2005;168:193-199.

-17 Sambasivan R, Tajbakhsh S: Skeletal muscle stem cell birth and properties. Semin Cell Dev Biol 2007; 18:870-882.

18 Buckingham M: Skeletal muscle progenitor cells and the role of Pax genes. C R Biol 2007; 330:530-533.

19 Collins CA, Olsen I, Zammit PS, Heslop L, Petrie A, Partridge TA, Morgan JE: Stem cell function, self-renewal, and behavioral heterogeneity of cells from the adult muscle satellite cell niche. Cell 2005;122:289-301.

-20 Shefer G, Yablonka-Reuveni Z: Isolation and culture of skeletal muscle myofibers as a means to analyze satellite cells. Methods Mol Biol 2005;290:281-304.

-21 Zammit PS, Golding JP, Nagata Y, Hudon V, Partridge TA, Beauchamp JR: Muscle satellite cells adopt divergent fates: a mechanism for self-renewal? J Cell Biol 2004;166:347357.

22 Seale P, Rudnicki MA: A new look at the origin, function, and 'stem-cell' status of muscle satellite cells. Dev Biol 2000;218:115-124.

-23 Cooper RN, Tajbakhsh S, Mouly V, Cossu G, Buckingham M, Butler-Browne GS: In vivo satellite cell activation via Myf5 and MyoD in regenerating mouse skeletal muscle. J Cell Sci 1999;112:2895-2901.

-24 Smith CK, 2nd, Janney MJ, Allen RE: Temporal expression of myogenic regulatory genes during activation, proliferation, and differentiation of rat skeletal muscle satellite cells. J Cell Physiol 1994;159:379-385.
5 Yablonka-Reuveni Z, Rivera AJ: Temporal expression of regulatory and structural muscle proteins during myogenesis of satellite cells on isolated adult rat fibers. Dev Biol 1994;164:588-603.

-26 Asakura A, Komaki M, Rudnicki M: Muscle satellite cells are multipotential stem cells that exhibit myogenic, osteogenic, and adipogenic differentiation. Differentiation 2001;68:245-253.

27 Perry RL, Rudnick MA: Molecular mechanisms regulating myogenic determination and differentiation. Front Biosci 2000;5: D750-D767.

28 Lin H, Yutzey KE, Konieczny SF: Musclespecific expression of the troponin I gene requires interactions between helix-loop-helix muscle regulatory factors and ubiquitous transcription factors. Mol Cell Biol 1991;11: 267-280.

29 Seward DJ, Haney JC, Rudnicki MA, Swoap SJ: bHLH transcription factor MyoD affects myosin heavy chain expression pattern in a muscle-specific fashion. Am J Physiol Cell Physiol 2001;280:C408-C413.

30 Pradat PF, Barani A, Wanschitz J, Dubourg O, Lombes A, Bigot A, Mouly V, Bruneteau $G$, Salachas F, Lenglet T, Meininger V, Butler-Browne G: Abnormalities of satellite cells function in amyotrophic lateral sclerosis. Amyotroph Lateral Scler 2011;12:264-271.

31 Manzano R, Toivonen JM, Olivan S, Calvo AC, Moreno-Igoa M, Munoz MJ, Zaragoza P, Garcia-Redondo A, Osta R: Altered expression of myogenic regulatory factors in the mouse model of amyotrophic lateral sclerosis. Neurodegener Dis 2011;8:386-396.

32 Manzano R, Toivonen JM, Calvo AC, Olivan S, Zaragoza P, Munoz MJ, Montarras D, Osta R: Quantity and activation of myofiber-associated satellite cells in a mouse model of amyotrophic lateral sclerosis. Stem Cell Rev 2012;8:279-287.

-33 Manzano R, Toivonen JM, Calvo AC, MianaMena FJ, Zaragoza P, Munoz MJ, Montarras D, Osta R: Sex, fiber-type, and age dependent in vitro proliferation of mouse muscle satellite cells. J Cell Biochem 2011;112:2825-2836.

34 Montarras D, Morgan J, Collins C, Relaix F, Zaffran S, Cumano A, Partridge T, Buckingham M: Direct isolation of satellite cells for skeletal muscle regeneration. Science 2005; 309:2064-2067.

35 Megeney LA, Kablar B, Garrett K, Anderson JE, Rudnicki MA: MyoD is required for myogenic stem cell function in adult skeletal muscle. Genes Dev 1996;10:1173-1183.

- 36 Roberts MD, Dalbo VJ, Hassell SE, Brown R, Kerksick CM: Effects of preexercise feeding on markers of satellite cell activation. Med Sci Sports Exerc 2010;42:1861-1869.

37 Calvo AC, Moreno-Igoa M, Manzano R, Ordovas L, Yague G, Olivan S, Munoz MJ, Zaragoza P, Osta R: Determination of protein and RNA expression levels of common housekeeping genes in a mouse model of neurodegeneration. Proteomics 2008;8:4338-4343.
38 Manzano R, Toivonen JM, Calvo AC, Munoz MJ, Zaragoza P, Osta R: Housekeeping gene expression in myogenic cell cultures from neurodegeneration and denervation animal models. Biochem Biophys Res Commun 2011;407:758-763.

39 Vandesompele J, De Preter K, Pattyn F, Poppe B, Van Roy N, De Paepe A, Speleman F: Accurate normalization of real-time quantitative RT-PCR data by geometric averaging of multiple internal control genes. Genome Biol 2002;3:RESEARCH0034.

40 Livak KJ, Schmittgen TD: Analysis of relative gene expression data using real-time quantitative PCR and the 2(-Delta Delta C(T)) method. Methods 2001;25:402-408.

41 Olguin HC, Olwin BB: Pax-7 up-regulation inhibits myogenesis and cell cycle progression in satellite cells: a potential mechanism for self-renewal. Dev Biol 2004;275:375-388.

$\checkmark 42$ Zammit PS, Relaix F, Nagata Y, Ruiz AP, Collins CA, Partridge TA, Beauchamp JR: Pax7 and myogenic progression in skeletal muscle satellite cells. J Cell Sci 2006;119:1824-1832.

-43 Turner BJ, Lopes EC, Cheema SS: Neuromuscular accumulation of mutant superoxide dismutase 1 aggregates in a transgenic mouse model of familial amyotrophic lateral sclerosis. Neurosci Lett 2003;350:132-136.

44 Frey D, Schneider C, Xu L, Borg J, Spooren W, Caroni P: Early and selective loss of neuromuscular synapse subtypes with low sprouting competence in motoneuron diseases. J Neurosci 2000;20:2534-2542.

45 Hegedus J, Putman CT, Gordon T: Time course of preferential motor unit loss in the SOD1 G93A mouse model of amyotrophic lateral sclerosis. Neurobiol Dis 2007;28:154164.

46 Gordon T, Ly V, Hegedus J, Tyreman N: Early detection of denervated muscle fibers in hindlimb muscles after sciatic nerve transection in wild type mice and in the G93A mouse model of amyotrophic lateral sclerosis. Neurol Res 2009;31:28-42.

47 Gurney ME: Transgenic animal models of familial amyotrophic lateral sclerosis. J Neurol 1997;244(suppl 2):S15-S20.

48 Atkin JD, Scott RL, West JM, Lopes E, Quah AK, Cheema SS: Properties of slow- and fasttwitch muscle fibres in a mouse model of amyotrophic lateral sclerosis. Neuromuscul Disord 2005;15:377-388.

49 Burkholder TJ, Fingado B, Baron S, Lieber RL: Relationship between muscle fiber types and sizes and muscle architectural properties in the mouse hindlimb. J Morphol 1994; 221:177-190.

50 Hegedus J, Putman CT, Gordon T: Progressive motor unit loss in the G93A mouse model of amyotrophic lateral sclerosis is unaffected by gender. Muscle Nerve 2009;39:318327. 
51 Pun S, Santos AF, Saxena S, Xu L, Caroni P: Selective vulnerability and pruning of phasic motoneuron axons in motoneuron disease alleviated by CNTF. Nat Neurosci 2006;9: 408-419.

52 McGeachie JK: Sustained cell proliferation in denervated skeletal muscle of mice. Cell Tissue Res 1989;257:455-457.

53 Wu J, Sun X, Zhong S: Changes in muscle satellite cells in denervated and innervated muscles (in Chinese). Zhongguo Xiu Fu Chong Jian Wai Ke Za Zhi 2006;20:10471051.

54 Borisov AB, Dedkov EI, Carlson BM: Abortive myogenesis in denervated skeletal muscle: differentiative properties of satellite cells, their migration, and block of terminal differentiation. Anat Embryol (Berl) 2005; 209:269-279.

55 Cova E, Ghiroldi A, Guareschi S, Mazzini G, Gagliardi S, Davin A, Bianchi M, Ceroni M, Cereda C: G93A SOD1 alters cell cycle in a cellular model of amyotrophic lateral sclerosis. Cell Signal 2010;22:1477-1484.

56 Aragno M, Mastrocola R, Catalano MG, Brignardello E, Danni O, Boccuzzi G: Oxidative stress impairs skeletal muscle repair in diabetic rats. Diabetes 2004;53:1082-1088.
57 Langen RC, Schols AM, Kelders MC, Van Der Velden JL, Wouters EF, Janssen-Heininger YM: Tumor necrosis factor-alpha inhibits myogenesis through redox-dependent and -independent pathways. Am J Physiol Cell Physiol 2002;283:C714-C721.

58 Sestili P, Barbieri E, Martinelli C, Battistelli M, Guescini M, Vallorani L, Casadei L, D’Emilio A, Falcieri E, Piccoli G, Agostini D, Annibalini G, Paolillo M, Gioacchini AM, Stocchi V: Creatine supplementation prevents the inhibition of myogenic differentiation in oxidatively injured $\mathrm{C} 2 \mathrm{C} 12$ murine myoblasts. Mol Nutr Food Res 2009;53:11871204.

59 Naryzhny SN, Zhao H, Lee H: Proliferating cell nuclear antigen (PCNA) may function as a double homotrimer complex in the mammalian cell. J Biol Chem 2005;280:1388813894.

60 Fox JT, Lee KY, Myung K: Dynamic regulation of PCNA ubiquitylation/deubiquitylation. FEBS Lett 2011;585:2780-2785.

-61 Bendotti C, Marino M, Cheroni C, Fontana E, Crippa V, Poletti A, De Biasi S: Dysfunction of constitutive and inducible ubiquitinproteasome system in amyotrophic lateral sclerosis: implication for protein aggregation and immune response. Prog Neurobiol 2012; 97:101-126.

-62 Guo K, Wang J, Andres V, Smith RC, Walsh $\mathrm{K}$ : Myod-induced expression of $\mathrm{p} 21$ inhibits cyclin-dependent kinase activity upon myocyte terminal differentiation. Mol Cell Biol 1995;15:3823-3829.
63 Halevy O, Novitch BG, Spicer DB, Skapek SX, Rhee J, Hannon GJ, Beach D, Lassar AB: Correlation of terminal cell cycle arrest of skeletal muscle with induction of p21 by MyoD. Science 1995;267:1018-1021.

64 Krivickas LS, Yang JI, Kim SK, Frontera WR: Skeletal muscle fiber function and rate of disease progression in amyotrophic lateral sclerosis. Muscle Nerve 2002;26:636-643.

65 Huang YC, Dennis RG, Baar K: Cultured slow vs. Fast skeletal muscle cells differ in physiology and responsiveness to stimulation. Am J Physiol Cell Physiol 2006; 291:C11-C17.

66 Kalhovde JM, Jerkovic R, Sefland I, Cordonnier C, Calabria E, Schiaffino S, Lomo T: 'Fast' and 'slow' muscle fibres in hindlimb muscles of adult rats regenerate from intrinsically different satellite cells. J Physiol 2005; 562:847-857.

67 Dobrowolny G, Aucello M, Rizzuto E, Beccafico S, Mammucari C, Boncompagni S, Belia S, Wannenes F, Nicoletti C, Del Prete Z, Rosenthal N, Molinaro M, Protasi F, Fano G, Sandri M, Musaro A: Skeletal muscle is a primary target of SOD1G93A-mediated toxicity. Cell Metab 2008;8:425-436. 